\title{
FAKTOR-FAKTOR YANG MEMPENGARUHI BUYING DECISION KONSUMEN GREEN PRODUCT DI JAKARTA
}

\author{
Annisa Shofi Ayuningtyas dan Tommy Setiawan Ruslim \\ Program Studi Manajemen Fakultas Ekonomi Universitas Tarumanagara, Jakarta \\ Email: annisa.115170414@stu.untar.ac.id
}

\begin{abstract}
Indonesian people are still less involved in the practice of minimizing ecosystem damage, such as not switching to using green products to reduce plastic waste. The number of green products sold in Indonesia itself is not small, but the demand is not too much. In fact, by increasing consumer purchasing decisions for green products, it can help Indonesia become a more environmentally friendly country. The purpose of this study was to examine the effect of environmental consciousness, eco-label, attitude, green advertising, and price on green product consumer buying decisions. This study uses Structural Equation Modeling (SEM) to analyze the hypothesis model with SmartPLS. This study used 260 samples obtained through the distribution of online questionnaires. The results of this study indicate that environmental consciousness, attitude, and price positively and significantly affect the buying decisions of green products consumers, while eco-labels, and green advertising positively but not significantly affect the buying decisions of green products consumers.
\end{abstract}

Keywords: Environmental Consciousness, Attitude, Price, Buying Decision, Green Product.

Abstrak: Masyarakat Indonesia masih kurang terlibat dalam praktik meminimalisir kerusakan ekosistem, seperti belum beralih menggunakan produk ramah lingkungan untuk mengurangi sampah plastik. Produk ramah lingkungan yang dijual di Indonesia sendiri jumlahnya tidak sedikit, namun peminatnya belum terlalu banyak. Padahal dengan meningkatkan keputusan pembelian konsumen terhadap green product, dapat membantu Indonesia menjadi negara yang lebih ramah lingkungan. Tujuan penelitian ini adalah untuk menguji pengaruh dari environmental consciousness, eco-label, attitude, green advertising, dan price terhadap buying decision konsumen green product. Penelitian ini menggunakan Structural Equation Modeling (SEM) untuk menganalisis model hipotesis dengan SmartPLS. Penelitian ini menggunakan 260 sampel yang didapatkan melalui pedistribusian kuesioner secara online. Hasil dari penelitian ini menunjukkan bahwa environmental consciousness, attitude, dan price secara positif dan signifikan mempengaruhi buying decision konsumen green product, serta eco-label, dan green advertising secara positif namun tidak signifikan mempengaruhi buying decision konsumen green product.

Kata Kunci: Kesadaran Lingkungan, Sikap, Harga, Keputusan Pembelian, Produk Ramah Lingkungan. 


\section{LATAR BELAKANG}

Sampah merupakan permasalahan yang dihadapi oleh hampir seluruh negara di dunia, terutama bagi negara dengan jumah penduduk yang banyak. Semakin banyak penduduk di suatu negara maka sampah yang dihasilkanpun akan semakin banyak jika tidak bisa dikelola dengan baik. Pada tahun 2016, Indonesia menduduki peringkat ke-5 sebagai negara dengan penghasil sampah plastik terbanyak. Negara Indonesia menduduki posisi ke-133 dari 180 negara dalam Most Environmentally Friendly Countries 2021. Maka dapat disimpulkan masyarakat Indonesia masih kurang terlibat dalam praktik meminimalisir kerusakan ekosistem, seperti belum beralih menggunakan produk ramah lingkungan atau green product untuk mengurangi sampah plastik. Produk ramah lingkungan atau yang sering disebut dengan green product yang dijual di Indonesia sendiri jumlahnya tidak sedikit, namun peminatnya belum terlalu banyak. Padahal dengan meningkatkan keputusan pembelian konsumen terhadap green product di Indonesia, dapat membantu Indonesia menjadi negara yang lebih ramah lingkungan.

Produk yang ramah lingkungan berarti produk tersebut tidak membahayakan lingkungan alam, membantu melestarikan sumber daya seperti air dan energi, dan mencegah kontribusi terhadap polusi udara, air, dan tanah. Beberapa contoh produk ramah lingkungan antara lain produk organik, lampu hemat energi, produk herbal, deterjen ramah lingkungan, sedotan reusable, tumbler, dan masih banyak lagi. Menurut Lai dan Cheng (2016), keputusan pembelian atau buying decision terhadap produk ramah lingkungan berkaitan dengan konsumen yang peduli lingkungan dan mencoba menggunakan keputusan pembelian mereka untuk membawa perubahan. Pembelian produk ramah lingkungan menjadi solusi efektif dalam mengurangi beban lingkungan akibat aktivitas manusia dalam produksi dan konsumsi produk (Ho et al., 2010).

Buying decision atau keputusan pembelian produk ramah lingkungan oleh konsumen tidak hanya bergantung pada persepsi dan sikap mereka terhadap produk ramah lingkungan, tetapi faktor-faktor lain seperti harga produk, ketersediaannya, kegiatan promosi, masalah sosial dan tingkat kesadaran tentang keputusan dan perilaku konsumsi dapat berkontribusi dalam keputusan pembelian mereka (Tan et al., 2019).

Dengan mengetahui faktor-faktor yang dipertimbangkan konsumen dalam memberikan keputusan pada pembeliannya, maka perusahaan dapat menyusun strategi yang tepat untuk menarik perhatian pelanggan. Berdasarkan penjabaran tersebut, rumusan masalah pada penelitian ini sebagai berikut: "Apakah environmental consciousness, eco-label, attitude, green advertising, dan price memiliki pengaruh terhadap buying decision konsumen green product di Jakarta?"

\section{KAJIAN TEORI}

Penelitian ini berpegang pada Theory of Planned Behavior (TPB). TPB dikembangkan dari Theory of Reasoned Action (TRA), dan telah banyak digunakan untuk mempelajari behavioral intentions dan actual behavior. Actual behavior ditentukan oleh behavioral intentions, dan salah satu faktor penentu behavioral intentions adalah attitudes toward 
behavior (Ajzen, 1991). Model TPB banyak digunakan untuk mengeksplorasi proenvironmental behaviors.

Attitudes mengacu pada keyakinan individu tentang konsekuensi perilaku, dengan evaluasi pentingnya konsekuensi ini (Ajzen, 1991). Attitudes dipandang sebagai evaluasi pembelian produk ramah lingkungan dalam konteks memprediksi green purchase behavior (Sun dan Wang, 2019). Dalam penelitian ini attitude memiliki kaitan pada teori TPB karena mempengaruhi keputusan pembelian terhadap produk yang ditawarkan. Seseorang yang percaya bahwa suatu perilaku tertentu akan memberikan hasil yang positif, maka orang tersebut akan memiliki sikap yang baik terhadap perilaku tersebut, begitu pula sebaliknya. Semakin positif sikap konsumen terhadap green product maka akan semakin kuat niat mereka untuk membeli, dan memutuskan untuk membeli produk tersebut. Konsumen dengan sikap positif terhadap produk ramah lingkungan lebih bersedia untuk membeli produk tersebut.

\section{Buying Decision}

Menurut Harahap et al. (2017), buying decision didefinisikan sebagai sebuah proses pengambilan keputusan mengenai pembelian yang mencakup keputusan apa yang akan dibeli atau tidak dibeli.

\section{Environmental Conciousness}

Menurut Sanchez dan Lafuente (2010), environmental consciousness didefinisikan sebagai perilaku dimana seseorang cenderung untuk terlibat dalam perilaku pro-lingkungan. Pada penelitian Gan et al. (2008) terhadap green product di Selandia Baru, hasil penelitiannya menunjukkan bahwa environmental consciousness memiliki pengaruh yang positif terhadap buying decision.

H1: Environmental consciousness memiliki pengaruh yang positif dan signifikan terhadap buying decision green product di Jakarta

\section{Eco-Label}

Menurut Sonderskov dan Daugbjerg (2011), eco-label didefinisikan sebagai cara untuk memberikan informasi yang kredibel dan mudah diakses kepada konsumen tentang atribut lingkungan suatu produk. Pada penelitian Rathnayaka dan Wijethunga (2002) terhadap FMCG di Sri Lanka, hasil penelitiannya menunjukkan bahwa eco-label memiliki pengaruh yang positif terhadap buying decision.

$\mathrm{H} 2$ : Eco-label memiliki pengaruh yang positif dan signifikan terhadap buying decision green product di Jakarta

\section{Attitude}

Menurut Ajzen (1991), attitude didefinisikan sebagai sejauh mana seseorang memiliki evaluasi yang disukai atau tidak disukai dari suatu perilaku yang dimaksud. Pada penelitian Nawawi (2018) terhadap keputusan pembelian produk makanan dan minuman halal, hasil penelitiannya menunjukkan bahwa attitude memiliki pengaruh yang positif terhadap buying decision. 
H3: Attitude memiliki pengaruh yang positif dan signifikan terhadap buying decision green product di Jakarta

\section{Green Advertising}

Menurut Zinkhan dan Carlson (1995), green advertising didefinisikan sebagai pesan promosi yang dapat menarik kebutuhan dan keinginan konsumen yang peduli lingkungan. Pada penelitian Prihandono et al. (2020) terhadap industri air minum kemasan, hasil penelitiannya menunjukkan bahwa green advertising memiliki pengaruh yang positif terhadap buying decision.

H4: Green advertising memiliki pengaruh yang positif dan signifikan terhadap buying decision green product di Jakarta

\section{Price}

Menurut Amanah et al. (2017), price didefinisikan sebagai nilai produk yang mempengaruhi keuntungan pemasar dan juga menjadi pertimbangan konsumen untuk membeli suatu produk. Pada penelitian Mimi dan Daniaty (2017) terhadap keputusan pembelian konsumen Hypermart Puri Indah di Jakarta Barat, hasil penelitian menunjukkan bahwa price memiliki pengaruh yang positif terhadap buying decision.

H5: Price memiliki pengaruh yang positif dan signifikan terhadap buying decision green product di Jakarta

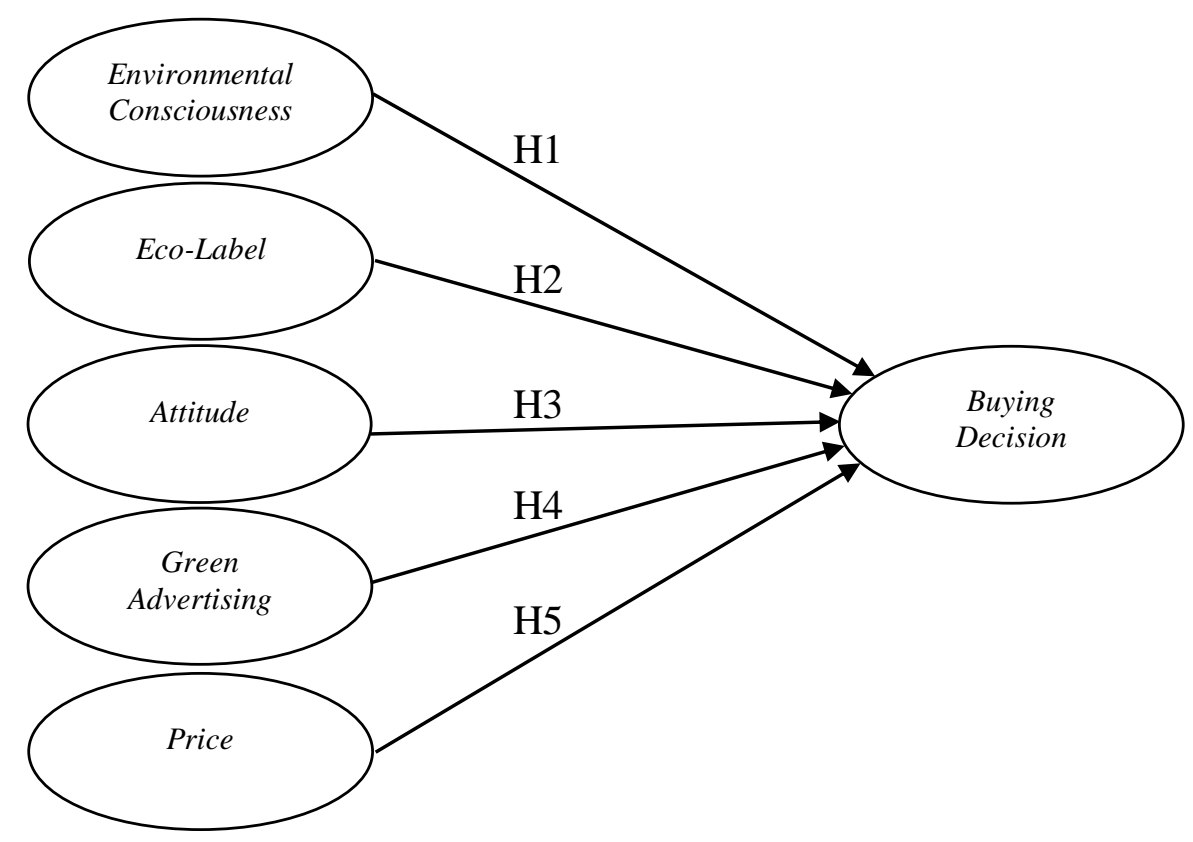

Gambar 1. Model Penelitian 


\section{METODOLOGI}

Penelitian ini bersifat deksriptif dengan menggunakan cross-sectional design, karena penelitian dilakukan dengan tujuan mendeskripsikan karakteristik atau fungsi pasar (Malhotra, 2010). Pendekatan penelitian ini adalah pendekatan kuantitatif dengan mendistribusikan kuesioner pada pengguna produk ramah lingkungan di Jakarta. Populasi dalam penelitian ini merupakan pengguna produk ramah lingkungan di Jakarta. Kuesioner dibuat dengan menggunakan google form dan disebarkan melalui media sosial seperti Line, WhatsApp, Instagram, dan Twitter kepada responden yang pernah membeli produk ramah lingkungan dan berdomisili di Jakarta. Dari 302 responden yang terkumpul, sampel yang digunakan sebanyak 260 responden karena telah memenuhi syarat pengisian kuesioner.

Penelitian ini menggunakan software SmartPLS dan menggunakan Structural Equation Model (SEM) sebagai teknik analisis data. Ghozali dan Latan (2015), menyatakan bahwa model evaluasi PLS dilakukan dengan menilai outer model dan inner model. Evaluasi model struktural atau inner model bertujuan untuk memprediksi hubungan antar variabel laten, sedangkan evaluasi model pengukuran atau outer model dilakukan untuk menilai validitas dan reliabilitas model (Ghozali dan Latan, 2015).

\section{Hasil Analisis Data}

Analisis data pada penelitian ini menggunakan teknik SEM. Menurut Ghozali dan Latan (2015), terdapat dua jenis analisis SEM yaitu outer model (measurement model) dan inner model (structural model). Hasil pada analisis outer model diukur dengan melihat nilai composite reliability dengan batas pengukuran diatas $0,70(>0,70)$, nilai cronbach's alpha diatas $0,60(>0,60)$, dan nilai average variance extracted (AVE) diatas 0,50 (>0,50).

Tabel 1

Hasil Analisis Data

\begin{tabular}{|c|c|c|c|}
\hline Variabel & Cronbach's Alpha & Composite Reliability & AVE \\
\hline $\begin{array}{c}\text { Environmental } \\
\text { consciousness }\end{array}$ & 0,902 & 0,927 & 0,718 \\
\hline Eco-label & 0,891 & 0,920 & 0,697 \\
\hline Attitude & 0,853 & 0,895 & 0,632 \\
\hline Green advertising & 0,926 & 0,945 & 0,773 \\
\hline Price & 0,867 & 0,910 & 0,716 \\
\hline Buying decision & 0,825 & 0,878 & 0,591 \\
\hline
\end{tabular}

Sumber: SmartPLS

Pengujian multikolinearitas dilakukan untuk mengetahui apakah terdapat korelasi antar variabel independen. Uji multikolinearitas dilihat dari nilai variance inflation factor (VIF) pada tiap variabel independen. Nilai variance inflation factor (VIF) tidak boleh lebih dari $5(<5)$ agar model dapat dikatakan baik. 
Tabel 2

Hasil Pengujian Multikolinearitas

\begin{tabular}{|c|c|c|}
\hline Variabel & VIF & Keterangan \\
\hline Environmental consciousness & 3,369 & Tidak ada multikolinearitas \\
\hline Eco-label & 3,901 & Tidak ada multikolinearitas \\
\hline Attitude & 3,523 & Tidak ada multikolinearitas \\
\hline Green advertising & 2,645 & Tidak ada multikolinearitas \\
\hline Price & 2,574 & Tidak ada multikolinearitas \\
\hline
\end{tabular}

Sumber: SmartPLS

Pengujian koefisien determinasi R-Square $\left(\mathrm{R}^{2}\right)$ digunakan dalam penelitian ini untuk mengetahui presentasi kontribusi antara variabel independen yaitu environmental consciousness, eco-label, attitude, green advertising, dan price untuk memprediksi terhadap variabel dependen yaitu buying decision. Berdasarkan hasil yang disajikan pada tabel di bawah, dapat diketahui bahwa pada nilai R-Square adalah sebesar 0,742. Hal ini menandakan bahwa sebesar 74,2\% dari variabel buying decision dapat dijelaskan oleh variabel environmental consciousness, eco-label, attitude, green advertising, dan price.

\section{Tabel 3}

Hasil Pengujian Koefisien Determinasi R-Square $\left(\mathbf{R}^{2}\right)$

\begin{tabular}{|c|c|c|}
\hline Variabel & $\mathbf{R}^{\mathbf{2}}$ & Keterangan \\
\hline Buying decision & 0,742 & Sedang \\
\hline
\end{tabular}

Sumber: SmartPLS

Pengujian Effect Size $\left(\mathrm{f}^{2}\right)$ digunakan untuk mengetahui seberapa besar pengaruh prediktor variabel laten, apakah prediktor variabel laten memiliki pengaruh yang kecil, sedang, atau besar. Effect size terbagi menjadi tiga kategori yaitu 0,02 menunjukkan pengaruh yang kecil, 0,15 menunjukkan pengaruh yang sedang, dan 0,35 menunjukkan pengaruh yang besar. Berdasarkan hasil pengujian, dapat disimpulkan bahwa keakuratan variabel environmental consciousness memiliki efek kecil karena nilai effect size lebih dari 0,02 (>0,02), eco-label tidak memiliki efek karena nilai effect size kurang dari 0,02 (>0,02), attitude memiliki efek kecil karena nilai effect size lebih dari 0,02 (>0,02), green advertising tidak memiliki efek karena nilai effect size kurang dari 0,02 (>0,02), dan price memiliki efek kecil karena nilai effect size lebih dari 0,02 (>0,02). 
Tabel 4

Hasil Pengujian Effect Size

\begin{tabular}{|c|c|}
\hline Variabel & Effect Size $\left(\mathbf{f}^{\mathbf{2}}\right)$ \\
\hline Environmental consciousness $\rightarrow$ Buying decision & 0,102 \\
\hline Eco-label $\rightarrow$ Buying decision & 0,008 \\
\hline Attitude $\rightarrow$ Buying decision & 0,068 \\
\hline Green advertising $\rightarrow$ Buying decision & 0,002 \\
\hline Price $\rightarrow$ Buying decision & 0,129 \\
\hline
\end{tabular}

Sumber: SmartPLS

Untuk menguji hipotesis yang telah dirumuskan dalam penelitian memiliki pengaruh yang positif atau negatif serta bersifat signifikan atau tidak signifikan, dapat diukur dengan melihat nilai path coefficient, nilai t-statistics dan p-value dengan menggunakan metode analisis bootstrapping pada SmartPLS. Nilai path coefficient diatas 0, batas minimal nilai tstatistics yaitu 1,65 (>0,60) dan nilai p-value dengan nilai batas maksimal $0,05(<0,50)$.

Tabel 5

\section{Hasil Pengujian Hipotesis}

\begin{tabular}{|c|c|c|c|c|c|}
\hline Hipotesis & Pernyataan Hipotesis & $\begin{array}{c}\text { Path } \\
\text { Coefficient }\end{array}$ & $\begin{array}{c}\mathbf{t}- \\
\text { statistics }\end{array}$ & $\begin{array}{c}\text { p- } \\
\text { values }\end{array}$ & Hasil \\
\hline $\mathrm{H} 1$ & $\begin{array}{l}\text { Environmental consciousness } \\
\text { memiliki pengaruh yang positif } \\
\text { dan signifikan terhadap buying } \\
\text { decision green product di } \\
\text { Jakarta }\end{array}$ & 0,297 & 4,025 & 0,000 & Didukung \\
\hline $\mathrm{H} 2$ & $\begin{array}{l}\text { Eco-label memiliki pengaruh } \\
\text { yang positif dan signifikan } \\
\text { terhadap buying decision green } \\
\text { product di Jakarta }\end{array}$ & 0,092 & 1,182 & 0,238 & $\begin{array}{c}\text { Tidak } \\
\text { Didukung }\end{array}$ \\
\hline H3 & $\begin{array}{l}\text { Attitude memiliki pengaruh } \\
\text { yang positif dan signifikan } \\
\text { terhadap buying decision green } \\
\text { product di Jakarta }\end{array}$ & 0,249 & 3,441 & 0,001 & Didukung \\
\hline $\mathrm{H} 4$ & $\begin{array}{l}\text { Green advertising memiliki } \\
\text { pengaruh yang positif dan } \\
\text { signifikan terhadap buying } \\
\text { decision green product di } \\
\text { Jakarta }\end{array}$ & 0,037 & 0,532 & 0,595 & $\begin{array}{c}\text { Tidak } \\
\text { Didukung }\end{array}$ \\
\hline H5 & $\begin{array}{l}\text { Price memiliki pengaruh yang } \\
\text { positif dan signifikan terhadap } \\
\text { buying decision green product } \\
\text { di Jakarta }\end{array}$ & 0,292 & 4,177 & 0,000 & Didukung \\
\hline
\end{tabular}

Sumber: SmartPLS 
Hasil perhitungan pada tabel di atas menunjukkan bahwa H1, H3, dan $\mathrm{H} 5$ didukung, sedangkan $\mathrm{H} 2$ dan $\mathrm{H} 4$ tidak didukung. Pada H1, H3, dan H5, nilai path coefficient diatas 0 , nilai t-statistic pada tiap variabel berada diatas $1,65(>1,65)$ dan nilai p-value dibawah $0,05(<$ $0,05)$, maka dapat disimpulkan bahwa terdapat hubungan yang positif dan signifikan variabel environmental consciousness, attitude, dan price terhadap buying decision. Sedangkan pada $\mathrm{H} 2$ dan $\mathrm{H} 4$, nilai path coefficient diatas 0 , nilai t-statistic pada tiap variabel berada dibawah $1,65(<1,65)$ dan nilai p-value diatas $0,05(>0,05)$, maka dapat disimpulkan bahwa terdapat hubungan yang positif namun tidak signifikan variabel eco-label dan green advertising terhadap buying decision.

\section{DISKUSI}

Hasil dari pengujian hipotesis pertama (H1) adalah didukung, maka variabel environmental consciousness memiliki pengaruh yang positif dan signifikan terhadap buying decision. Hipotesis tersebut diperkuat dengan penelitian Gan et al. (2008) terhadap green product di Selandia Baru yang hasil penelitiannya menunjukkan bahwa environmental consciousness memiliki pengaruh yang positif terhadap buying decision.

Hasil dari pengujian hipotesis kedua (H2) adalah tidak didukung, maka variabel ecolabel memiliki pengaruh yang positif namun tidak signifikan terhadap buying decision. Hasil dari penelitian ini sesuai dengan penelitian Susilo (2016), dimana keputusan pembelian masyarakat Indonesia terhadap produk dengan ekolabel masih rendah.

Hasil dari pengujian hipotesis ketiga (H3) adalah didukung, maka variabel attitude memiliki pengaruh yang positif dan signifikan terhadap buying decision. Hipotesis tersebut diperkuat dengan penelitian Nawawi (2018) terhadap keputusan pembelian produk makanan dan minuman halal yang hasil penelitiannya menunjukkan bahwa attitude memiliki pengaruh yang positif terhadap buying decision.

Hasil dari pengujian hipotesis keempat (H4) adalah tidak didukung, maka variabel green advertising memiliki pengaruh yang positif namun tidak signifikan terhadap buying decision. Hasil dari penelitian ini sesuai dengan hasil penelitian Wahab et al. (2017) dimana green advertising tidak berpengaruh secara signifikan terhadap keputusan pembelian green product di kota Palembang.

Hasil dari pengujian hipotesis kelima (H5) adalah didukung, maka variabel price memiliki pengaruh yang positif dan signifikan terhadap buying decision. Hipotesis tersebut diperkuat oleh penelitian Mimi dan Daniaty (2017) terhadap keputusan pembelian konsumen Hypermart Puri Indah di Jakarta Barat yang hasil penelitiannya menunjukkan bahwa price memiliki pengaruh positif terhadap buying decision.

\section{PENUTUP}

Berdasarkan hasil penelitian yang telah dijabarkan, maka dapat disimpulkan bahwa environmental conciousness, attitude, dan price merupakan predkiktor yang positif dan signifikan terhadap buying decision. Sedangkan eco-label dan green advertising merupakan prediktor yang positif namun tidak signifikan terhadap buying decision. 
Hal ini bisa terjadi karena label ramah lingkungan seperti contohnya label daur ulang atau label makanan organik masih jarang ditemui di Indonesia. Karena memang tidak semua produk ramah lingkungan memiliki ekolabel, dikarenakan membutuhkan proses yang panjang serta biaya yang tidak sedikit. Selanjutnya, dibandingkan dengan produk lain, iklan mengenai produk ramah lingkungan atau green advertising masih terbilang sedikit di Indonesia.

Saran bagi penelitian selanjutnya adalah untuk menggunakan variabel lainnya yang berpotensi memiliki pengaruh yang sama. Disarankan juga bagi penelitian selanjutnya untuk melakukan penambahan sampel penelitian yang jumlahnya lebih dari 260 responden. Selain itu disarankan juga untuk memperluas populasi penelitian. Saran bagi perusahaan yang memproduksi green product adalah untuk memberikan penjelasan kepada konsumen mengenai masalah lingkungan yang dapat teratasi jika konsumen melakukan pembelian green product, disarankan juga agar perusahaan dapat memberikan penjelasan kepada konsumen mengenai apa saja fungsi dan manfaat dari fitur unik pada green product, serta disarankan juga agar perusahaan memberikan penjelasan mengenai keuntungan atau manfaat apa saja yang didapatkan konsumen dengan membeli green product.

\section{DAFTAR PUSTAKA}

Ajzen, I. (1991). The theory of planned behavior. Organizational Behavior and Human Decision Processes, 50, 179-211.

Amanah, D., Harahap, D. A., \& Lisnawati, D. (2017). Exploring Online Purchase Decision Among University Students in Indonesia. Journal of Humanities and Social Science, 22(12), 72-77.

Gan, C., Wee, H. Y., Ozanne, L., \& Kao, T. H. (2008). Consumers' purchasing behavior towards green products in New Zealand. Innovative Marketing, 4(1), 93-102.

Ghozali, I., \& Latan, H. (2015). Konsep, Teknik, dan Aplikasi Menggunakan Program SmartPLS 3.0 Untuk Penelitian Empiris (Edisi 2). Semarang: Badan Penerbit Universitas Diponegoro Semarang.

Harahap, D. A., Hurriyati, R., Gaffar, V., \& Amanah, D. (2017). The Effect of Location and Products Completeness to Consumer Buying Decision of Small and Medium Enterprise Market. 2nd Global Conference on Business, Management, and Entrepreneurship, 3033.

Ho, L. W. P., Dickinson, N. M., \& Chan, G. Y. S. (2010). Green procurement in the Asian public sector and the Hong Kong private sector. Natural Resources Forum, 33, 24-38.

Lai, C. K. M., \& Cheng, E. W. L. (2016). Green purchase behavior of undergraduate students in Hong Kong. The Social Science Journal, 53, 67-76.

Malhotra, N. K. (2010). Marketing Research: An Applied Orientation (6th ed.). Pearson Education.

Mimi, S. A., \& Daniaty, F. (2017). Pengaruh Harkga, Pelayanan, Lokasi, dan Keragaman Produk Terhadap Keputusan Pembelian Pada Hypermart Puri Indah di Jakarta Barat. Jurnal Ekonomi, 22(1), 124-131.

National Geographic. (2020). U.S. generates more plastic trash than any other nation, report finds (Retrieved from: https://www.nationalgeographic.com/12-3-2021) 
Nawawi, M. T. (2018). Analisis Faktor-Faktor yang Mempengaruhi Keputusan Konsumen dalam Pembelian Produk Makanan dan Minuman Halal di Jakarta. Jurnal Muara Ilmu Ekonomi dan Bisnis, 2(1), 72-80.

Prihandono, D., Wijaya, A. P., Rizqiana, I., Yahya, W. K., \& Prabumenang, A. K. R. (2020). Green Marketing Tools Effect on Consumer Buying Decision in The Bottled Water Industry. Humanities \& Social Sciences Reviews, 8(4), 537-546.

Rathnayaka, R. M. U. M. K, \& Wijethunga, W. M. N. M. (2020). Consumer's Green Product Buying Decision: Impact of Selected Factors. Wayamba Journal of Management, 11(2), 37-46.

Sanchez, M. J., \& Lafuente, R. (2010). Defining and measuring environmental consciousness. Revista Internacional de Sociologia, 68(3), 731-755.

Sonderskov, K. M., \& Daugbjerg, C. (2011). The state and consumer confidence in eco labeling: Organic labeling in Denmark, Sweden, The United Kingdom and The United States. Agriculture and Human Values, 28, 507-517.

Sun, Y., \& Wang, S. (2019). Understanding consumers' intentions to purchase green products in the social media marketing context. Asia Pacific Journal of Marketing and Logistics, 32(4), 860-878.

Susilo, B. O. (2016). Pengetahuan Ecolabel di Indonesia Versus Pengetahuan Ecolabel di Negara Maju Yang Berpengaruh Pada Niat dan Keputusan Pembelian. Journal of Management Studies 10(2), 113-124.

Tan, C. N. L., Ojo, A. O., \& Thurasamy, R. (2019). Determinants of green product buying decision among young consumers in Malaysia. Young Consumers, 20(2), 121-137.

Wahab, Z., Tama, R. A., Shihab, M. S., Widad, A., Nofiawaty, \& Diah, Y. M. (2017). Analysis The Effect of Environmental Concern and Green Advertising to Green Purchasing in Palembang City. Sriwijaya International Journal of Dynamic Economics and Business 1(3), 297-310.

World Population Review. (2021). Most Environmentally Friendly Countries 2021 (Retrieved from: https://worldpopulationreview.com/12-3-2021)

Zinkhan, G. M., \& Carlson, L. (1995). Green Advertising and the Reluctant Consumer. Journal of Advertising, 24(2), 1-6. 